\title{
DEVELOPMENT AND CHARACTERIZATION OF TOPICAL NANOPARTICULATE ANTIPSORIATIC POLYHERBAL CREAM
}

\author{
SHADAB KHAN ${ }^{1}$, GHAZALA MULLA ${ }^{2}$, KIRAN BHISE ${ }^{*}$
}

1Department of Pharmaceutics, M. C. E. Society's Allana College of Pharmacy, Pune, India, ${ }^{2}$ Department of Physiology, Z. V. M. Unani Medical College and Hospital, Pune, India

Email: ksbhise@rediffmail.com

Received: 22 Jan 2020, Revised and Accepted: 06 Mar 2020

\begin{abstract}
Objective: The lack of possible cure and associated disadvantages of allopathic medicines in the topical treatment of psoriasis has led to extensive research for anti-psoriatic activities of plant-based drugs. The present study was aimed to develop topical cream formulation containing the Nanostructured Lipid Carriers of Azadirachta indica leaves extract (AE), Lawsonia inermis leaves extract (LE) and fruit extract of Mallotus philippensis (ME) and assessing the antipsoriatic activity of prepared cream formulation.
\end{abstract}

Methods: The Drug loaded NLCs were prepared via hot homogenization technique and incorporated into the water in oil (w/o) cream base that was prepared by the emulsification method. Evaluation of cream formulation included advanced preclinical trials using Rat Ultraviolet Ray-B photodermatitis and Mousetail method, anti-lipid peroxidation assay, nitric oxide scavenging activity, cytotoxicity and DNA fragmentation on HaCat cell lines to ascertain antipsoriatic potential and in vitro drug diffusion.

Results: In spite of the low amount of the drug loading in NLCs their potency was much higher as displayed in Advanced Preclinical studies and cell line studies for psoriasis indicating the suitability of NLCs loaded creams for skin applications due to their various desirable effects on the skin. Occlusive properties of the prepared NLC on the skin provide an increase in drug penetration particularly via skin moisturization. The in vitro drug diffusion studies suggest the prolonged and almost complete release of AE, LE and ME from NLC based cream up to $24 \mathrm{~h}$ that was found to be $81.24 \pm 0.51 \%, 74.31 \pm 0.25 \%$ and $70.43 \pm 0.78 \%$ respectively. The literature survey supports the novelty of such topical anti-psoriatic polyherbal nanoparticulate cream.

Conclusion: It can be concluded that the AE, LE and ME loaded NLC based cream can be used for prolonged topical delivery of drugs for the management of Psoriasis.

Keywords: Herbal Anti-psoriatic Nanoparticulate Cream, Cell line study, Advanced Preclinical Trials

(C) 2020 The Authors. Published by Innovare Academic Sciences Pvt Ltd. This is an open access article under the CC BY license (http://creativecommons.org/licenses/by/4.0/) DOI: http://dx.doi.org/10.22159/ijap.2020v12i3.36911. Journal homepage: https://innovareacademics.in/journals/index.php/ijap

\section{INTRODUCTION}

Psoriasis is an autoimmune skin disease that causes scaling and inflammation of the skin and occurs when the immune system sends out faulty signals that speed up the growth cycle of skin cells than normal [1-2]. The body does not shed these excess skin cells, thereby resulting in the piling up of cells on the surface of the skin that pose the problem of poor topical drug permeability [1]. The lack of possible cure and associated disadvantages of allopathic medicines in the topical treatment of psoriasis has led to extensive research for anti-psoriatic activities of plant-based drugs [3-5]. The literature survey reveals the multitude of medicinal properties of Azadirachta indica, Lawsonia inermis, and Mallotus philippensis for the treatment of skin diseases as well as absence of such combination therapy [6]. The dried extracts of Azadirachta indica, Lawsonia inermis, and Mallotus philippensis act as anti-inflammatory agents due to the presence of flavonoids in them [7-9]. The permeability through the skin is improved through the NLC approach due to the improved lipophilicity as imparted by solid and liquid lipids $[10,11]$. The literature survey reveals that a maximum of $5-10 \%$ of the drug can be loaded in NLCs [12]. Our preliminary studies have shown the encouraging results for antipsoriatic potential of the dried extracts of Azadirachta indica, Lawsonia inermis, and Mallotus philippensis when loaded in Nanostructured Lipid Carriers $[13,14]$. The present study was aimed to develope topical cream formulation containing the Nanostructured Lipid Carriers of Azadirachta indica leaves extract (AE), Lawsonia inermis leaves extract ( $L E)$ and fruit extract of Mallotus philippensis (ME) and assessing the antipsoriatic activity of prepared cream formulation using cell line studies and preclinical trials on animal models.

\section{MATERIALS AND METHODS}

\section{Materials}

Dried herbs of Azadirachta indica Leaves, Lawsonia inermis Leaves and Mallotus philippensis powder were purchased from local vendors and authenticated (Ref No.: Bot/10/2017) from Department of Botany,
Savitribai Phule University of Pune, India. The solid lipids were obtained as gift samples from Gattefosse, France. Rest all chemicals were of AR grade and were purchased from Sigma Aldrich.

\section{Preparation of AE, LE and ME NLC loaded cream}

The AE, LE and ME loaded NLCs were prepared by the Hot Homogenization method using High-pressure homogenizer (Nitro Soavi, Italy) as described in our previous research work [14]. Cream enriched with AE, LE and ME loaded NLCs was prepared by the emulsification method. The aqueous phase was added dropwise to the oil phase at $65{ }^{\circ} \mathrm{C}$ with constant stirring. The AE, LE, and ME loaded NLCs were incorporated into the cream with stirring at 5000 rpm for 5 min using High-Speed Homogenizer (Ultra Turrex) and stirred to yield a cream containing a final concentration of $4.7 \%$ NLCs. Each $60 \mathrm{~g}$ of w/o Glycerol monostearate, Cetostearyl alcoholbased cream rich in vitamin E and honey with Polysorbate 80 as a surfactant contained $2 \mathrm{~g}$ of AE, LE and ME loaded NLCs $[8,15]$.

\section{Determination of $\mathrm{pH}$}

The $\mathrm{pH}$ of NLC loaded $\mathrm{W} / \mathrm{O}$ cream formulation and the cream base was by immersing the electrode of Digital pH meter 802 (EQUIPTRONICS, EQ-601) to a depth of $0.5 \mathrm{~cm}$ in a beaker containing cream. The determination was carried out in triplicate and the average of three readings was recorded [16].

\section{Determination of viscosity}

The viscosity of samples of NLC loaded cream was determined on the plate and cone Brookfield viscometer (Model CAP 2000+2) at a speed of $10,20,50$ and $100 \mathrm{rpm}$ for $10 \mathrm{sec}$ run time using spindle number 7 at $37^{\circ} \mathrm{C}$. The determinations were carried out in triplicate and the average of three readings was recorded $[17,18]$.

\section{Spreadability}

For the determination of spreadability, 1 gm of cream was applied in between two glass slides and was compressed to uniform thickness 
by placing 500 gm weight to the pan attached to the top plate and was subjected to pull with the help of string attached to the hook. The time in which the upper glass slide moves the lower plate to cover a distance of $14 \mathrm{cmWAS}$ noted. A shorter interval indicates better spreadability. The spreadability $(\mathrm{S})$ was calculated using the formula $[17,18]$ :

$$
S=w \frac{1}{t}
$$

Where,

S-spreadability

w-weight tied to an upper glass slide.

l-length moved on a glass slide

t-time taken.

\section{Tubeextrudability}

In the present study, the method adopted for evaluating cream formulation for extrude ability was based upon the quantity in percentage cream extruded from a tube on the application of finger pressure. The formulation understudy was filled in a clean, lacquered aluminum collapsible 5 grams tube with a nasal tip of 5 $\mathrm{mm}$ opening and apply the pressure on the tube with the help of a finger. Tube extrudability was then determined by measuring the amount of cream extruded through the tip when pressure was applied on the tube $[17,19]$.

\section{Drug content uniformity}

Drug content uniformity was performed according to the USP requirement for the cream formulation using uniformity for the content check Assay method by UV. In the filled tube sample was taken from the upper, middle and end portion and analyzed by UV Spectrophotometer. $3 \mathrm{~g}$ of each cream (equivalent $10 \mathrm{mg}$ of the drug) formulation were taken in $50 \mathrm{ml}$ volumetric flask containing $25 \mathrm{ml}$ PBS 6.8: Methanol and stirred for $30 \mathrm{~min}$ and allowed to stand for $24 \mathrm{~h}$. The volume was made up to $50 \mathrm{ml}$ and volume was made up to $50 \mathrm{ml}$ with the same solvent. The drug content was determined by measuring the absorbance at 214, 276 and $297 \mathrm{~nm}$ for the measurement of AE, LE and ME respectively using Double-beam UV spectrophotometer J V-530 Jasco Corporation, Tokyo, Japan. The amount of drug present in the formulation was checked by the percentage drug content study in the formulation $[18,20]$.

\section{In vitro cumulative \% drug diffusion of AE, LE and ME NLC} loaded cream

The in vitro release studies were performed using DBK Franz diffusion cell apparatus to evaluate the release profile of AE, LE and ME NLC incorporated cream. Dialysis membrane 70 (Hi-Media, Mumbai, India) having pore size $2.4 \mathrm{~nm}$ and a molecular weight cutoff 12,000 was used and mounted on the Franz diffusion cells. A phosphate buffer (PBS) pH 6.8: Methanol (7:3) was used as the receptor medium $(20 \mathrm{ml})$ being stirred at $200 \mathrm{rpm} .100 \mathrm{mg}$ of cream was used for the study. During the experiments, the solution in the receptor side was maintained at $37 \pm 0.5{ }^{\circ} \mathrm{C}$. At predetermined time intervals, $1 \mathrm{ml}$ of the samples were withdrawn from the receiver compartment and replaced by the same volume of freshly prepared PBS (pH 6.8): Methanol (7:3). The samples were analyzed by the UVVisible spectrophotometer (UV-1800, Shimadzu, Japan) at 214, 276 and $297 \mathrm{~nm}$ for the release of AE, LE and ME respectively $[18,19]$.

\section{Stability studies}

NLC based cream formulation was subjected to stability studies for 3 mo. The formulations were filled in wide-mouth glass bottles and were stored at a temperature of $37 \pm 0.5{ }^{\circ} \mathrm{C}$ and $75 \pm 5 \% \mathrm{RH}$. These samples were evaluated for appearance, $\mathrm{pH}$, viscosity, drug content, spreadability and in vitro drug release study [20,21].

\section{Lipid peroxidation assay}

Lipid peroxidation assay for NLC based cream was determined based on the amount of Thiobarbituric acid reactive substances. The HepG2 cells were seeded in 24-well culture plates at an initial density of $2 * 10^{5}$ cells $/ \mathrm{ml}$ and grown to approximately $80 \%$ confluence. Oxidative stress was induced by treating the cells with freshly prepared $\mathrm{H}_{2} \mathrm{O}_{2}$. The cells were pretreated with samples (AE, LE and ME NLC loaded cream) at indicated concentrations for 24 h. Fetal Bovine Serum-free Dulbecco's Modified Eagle's medium containing $\mathrm{H}_{2} \mathrm{O}_{2}(882 \mathrm{nM})$ was added to each well and the cell plate was incubated for $24 \mathrm{~h}$. The HepG2cells were lysed by using the freeze-thaw method. After analysis, $0.2 \mathrm{ml}$ of the cell suspension was added to the Thiobarituric acid reagent. This mixture was incubated at $90{ }^{\circ} \mathrm{C}$ for $1 \mathrm{~h}$, and then cooled. Four milliliters of a mixture of $\mathrm{n}$-butanol and pyridine $(15: 1, \mathrm{v} / \mathrm{v})$ were added and were centrifuged for $15 \mathrm{~min}$ and the absorbance was measured at $532 \mathrm{~nm}[22,23]$.

The percentage inhibition of lipid peroxidation was calculated using the following formula:

$$
\% \text { inhibition }=\frac{\text { Absorbance }(\text { control })-\text { Absorbance }(\text { sample })}{\text { Absorbance }(\text { control })} \times 100
$$

\section{Nitric oxide scavenging assay}

Accurately $200 \mu \mathrm{l}$ of 10 mmol sodium nitroprusside and $200 \mu \mathrm{l}$ of the test solution and reference standard of various concentrations were incubated at room temperature for $150 \mathrm{~min}$. About $500 \mu \mathrm{l}$ Griess reagent was added and was subjected to incubation for 10 min at room temperature. The absorbance was measured at $546 \mathrm{~nm}$. Test substances were replaced by Phosphate buffer solution $\mathrm{pH} 7.0$ for control [24].

The percentage inhibition of Nitric Oxide was calculated as follows:

$$
\% \text { inhibition }=\frac{\text { Absorbance }(\text { control })-\text { Absorbance }(\text { sample })}{\text { Absorbance }(\text { control })} \times 100
$$

\section{Cytotoxicity studies on HaCat cell lines}

HaCaT cell line was procured from ATCC, stock cells were cultured in Dulbecco's Modified Eagle's medium supplemented with $10 \%$ inactivated Fetal Bovine Serum, Penicillin $(100 \mathrm{IU} / \mathrm{ml})$, Streptomycin $(100 \mu \mathrm{g} / \mathrm{ml})$ in a humidified atmosphere of $5 \%$ Carbon dioxide at $37^{\circ} \mathrm{C}$. Serial two-fold dilutions $(0-100 \mu \mathrm{M})$ were prepared for carrying out cytotoxic studies. The monolayer cell culture was trypsinized and the cell count was adjusted to $1.0 \times 10^{5}$ cells $/ \mathrm{ml}$ using respective media containing $10 \%$ Fetal Bovine Serum. To each well of the 96 well microtiter plate, $100 \mu \mathrm{l}$ of the diluted cell suspension $(50,000$ cells/well) was added. After $24 \mathrm{~h}$, when a partial monolayer was formed, the supernatant was discarded, washed the monolayer once with medium and $100 \mu \mathrm{l}$ of different test concentrations of NLC loaded cream was added on to the partial monolayer in microtiter plates followed by incubation at $37^{\circ} \mathrm{C}$ for $24 \mathrm{~h}$ in $5 \%$ Carbon dioxide atmosphere. After incubation, the test solutions in the wells were discarded and $100 \mu \mathrm{l}$ of 3-[4, 5-dimethylthiazol-2-yl]-2, 5-diphenyl tetrazolium bromide $(5 \mathrm{mg} / 10 \mathrm{ml}$ of MTT in USP Phosphate buffer $\mathrm{pH} 7.0$ ) was added to each well. The plates were incubated for $4 \mathrm{~h}$ at $37{ }^{\circ} \mathrm{C}$ in $5 \%$ Carbon dioxide atmosphere. The supernatant was removed and $100 \mu \mathrm{l}$ of Dimethyl sulfoxide was added and the plates were gently shaken to solubilize the formed formazan. The absorbance was measured using a microplate reader at a wavelength of $590 \mathrm{~nm}$. The percentage growth inhibition was calculated using the following formula and concentration of test drug needed to inhibit cell growth by $50 \%\left(\mathrm{IC}_{50}\right)$ values were generated from the dose-response curves for each cell line [25, 26].

$$
\% \text { inhibition }=100-\frac{\text { OD of cream sample }}{\text { OD of control }} \times 100
$$

\section{DNA fragmentation studies on HaCat cell lines}

HaCat cells were seeded at a concentration of $1 \times 106$ per $35 \mathrm{~mm}$ dish incubated at $37{ }^{\circ} \mathrm{C} / 5 \%$ Carbon dioxide for $24 \mathrm{~h}$. The confluent cells grown after $24 \mathrm{~h}$ of incubation were treated with sample conc. $160 \mu \mathrm{g} / \mathrm{ml}, 320 \mu \mathrm{g} / \mathrm{ml}$ and control. After treatment, cells were trypsinized, and both adherent and floating cells were collected by centrifugation at $2000 \mathrm{rpm}$ for $5 \mathrm{~min}$. The cell pellet was suspended in $0.5 \mathrm{ml}$ lysis buffer $\mathrm{pH} 7.8$ containing a mixture of Tris-Hydrochloric acid $10 \mathrm{mmol}, \mathrm{pH} \mathrm{8}$; Ethylene diamine tetraacetic acid 20 mmol, pH 8.0; TritonX-100 $0.2 \%$ or Sodium- 
$\mathrm{N}$-lauroyl sarcosinate, 4M Sodium chloride, vortex vigorously and incubated at $50^{\circ} \mathrm{C}$ for $5 \mathrm{~min}$. To the lysate, $0.5 \mathrm{ml}$ of phenol chloroform iso-amyl alcohol was added and mixed for 2-3 min and centrifuged at $10000 \mathrm{rpm}$ for $15 \mathrm{~min}$ at $4{ }^{\circ} \mathrm{C}$. The upper aqueous layer was taken in a new tube, to which double the volume of cold $100 \%$ ethanol was added and $3 \mathrm{M}$ sodium acetate was added to make a final concentration of sodium acetate $0.3 \mathrm{M}$. The sample was incubated for 5-10 min at room temperature and centrifuged at $10000 \mathrm{rpm}$ for $15 \mathrm{~min}$. After removing the supernatant, the DNA pellets were washed with $70 \%$ ethanol and centrifuged at $5000 \mathrm{rpm}$ for $10 \mathrm{~min}$ followed by removal of supernatant and air drying of DNA pellets that were dissolved in tris buffer and separated by $2 \%$ agarose gel electrophoresis at 100 volts for $50 \mathrm{~min}[27,28]$.

\section{Mouse-tail model for psoriasis}

All procedures of the study were in accordance with the guidelines set by the CPCSEA and an approved IAEC protocol number (IAEC17-019). 15 male Swiss albino Mice were allowed to acclimatize for $5 \mathrm{~d}$ and randomly allotted to three groups, 6 mice per standard Group I, Clobetasol propionate $0.05 \%$ cream and AE, LE, and ME NLC loaded cream Group II and 6 mice for placebo control Group III. The samples were applied to tails treated locally at the rate of 2-5 mg per animal to the proximal part of the tail uniformly. For the contact time of $2 \mathrm{~h}$, a plastic cylinder was slipped over the tail and fixed with adhesive tape. At the end of contact time, the cylinders were removed and the tails were wiped with cotton. Mice were treated once daily, for $2 \mathrm{w}$. Two $\mathrm{h}$ after the last treatment the animals were sacrificed and the tails were fixed in $10 \%$ buffered formalin and processed for histopathology. Longitudinal sections of about $5 \mu \mathrm{m}$ thickness were prepared and stained with hematoxylin-eosin and permanent slides were prepared for evaluation. Sections were examined under a light microscope to observe alterations in epidermal thickness, elongation of ridges and orthokeratosis. The animals were also observed for mortality and clinical sign and changes in body weights [29].

\section{Rat ultraviolet ray B photo dermatitis model for psoriasis}

Healthy male Sprague Dawley rats weighing 150-200 gm were kept in $12 \mathrm{~h}$ light: $12 \mathrm{~h}$ dark cycle at 20.4 to $23.8^{\circ} \mathrm{C}$ temperature and 36 to 61 $\% \mathrm{RH}$ with the provision of food (ad libitum) and water (Reverse osmosis water treated with Ultraviolet light) were carefully maintained. All procedures of the study were in accordance with guidelines set by the CPCSEA and an approved IAEC protocol number (IAEC-17-009). The study design comprised of three groups, Group I $(2-5 \mathrm{mg} / \mathrm{kg}$ of Clobetasol propionate $0.05 \%$ cream as standard) 6 animals, Group II (2-5 mg/kg of AE, LE and ME NLC loaded cream) 6 animals and Group III (2-5 mg/kg of Placebo cream) 3 animals respectively. The hair on the dorsal skin was clipped and carefully shaved. An area $(1.5 \times 2.5 \mathrm{~cm})$ on one side of the flank was irradiated for $15 \mathrm{~min}(1.5 \mathrm{~J} / \mathrm{cm} 2)$ at a vertical distance of $20 \mathrm{~cm}$ with UV-B LAMPS. Biphasic erythema was observed. After $72 \mathrm{~h}$ irradiation, the test anti-psoriatic cream, standard cream, and placebo cream were applied at the $2-5 \mathrm{mg} /$ rat topically on the irradiated site daily once. The irradiated rats were sacrificed on day 11 after UV-B irradiation by CO2 anesthesia. Skin biopsies were taken immediately, and fixed in $10 \%$ formalin and embedded in paraffin. Tissue sections ( $4 \mu \mathrm{m}$ thick) were stained with hematoxylin and eosin. Sections were examined under a light microscope to observe alterations in epidermal thickness, elongation of ridges and orthokeratosis. Parameters evaluated included mortality and clinical signs observations and body weight. All the data were analyzed using one way ANOVA followed by Dunnett's Multiple Comparison test [30, 31].

\section{RESULTS AND DISCUSSION}

\section{Evaluation of AE, LE and ME NLC loaded cream}

The literature survey reveals that a maximum of $5-10 \%$ of the drug can be loaded in NLCs [12]. That is $2 \mathrm{~g}$ of NLC can contain a maximum of $200 \mathrm{mg}$ of the drug. For loading, the NLCs in suitable cream base $2 \mathrm{~g}$ of NLCs were loaded in $60 \mathrm{~g}$ of cream base. The NLC loaded w/o cream was evaluated for $\mathrm{pH}$, Physical appearance, Drug content, viscosity, spreadability, Drug diffusion, and Stability. The $\mathrm{pH}$ of NLC based cream was found to be $6.91 \pm 0.011$.

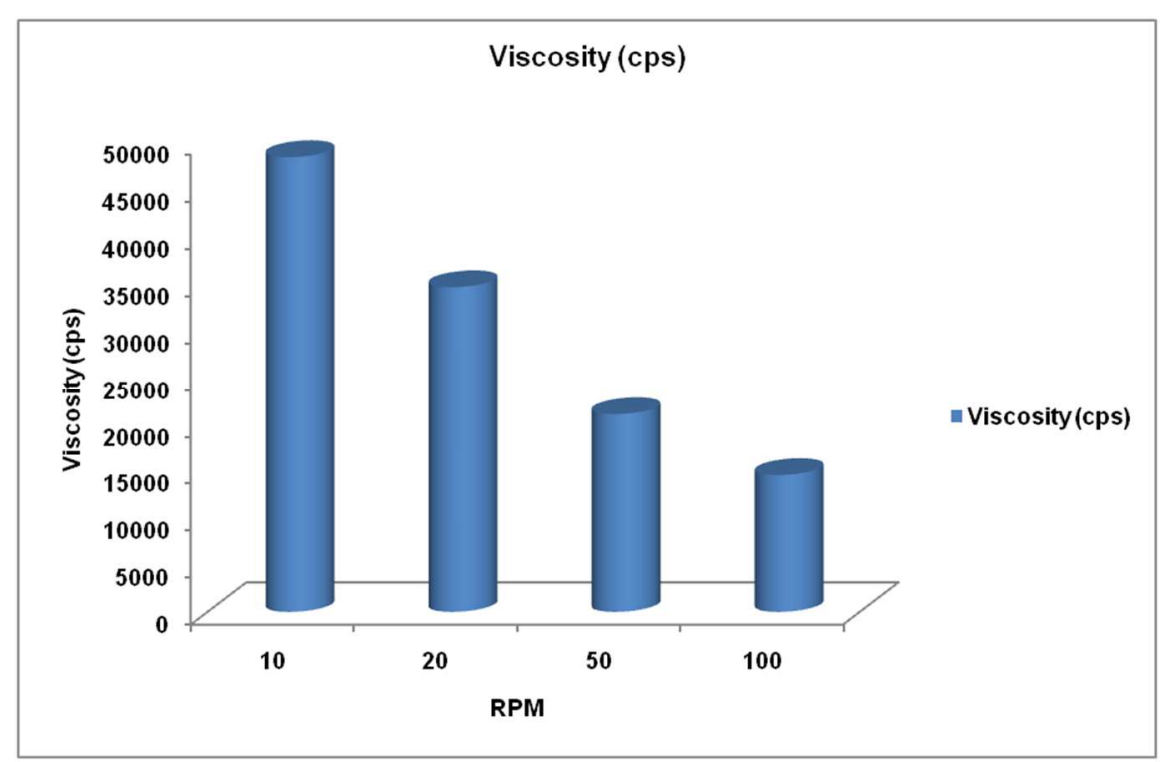

Fig. 1: Viscosity values of the AE, LE and ME NLC Incorporated cream at different rpm, Note: $(n=3)$ all data representing an average of 3 trials, given as mean $\pm \mathrm{SD}, \mathrm{AE}=$ Azadirachta indica extract, $\mathrm{LE}=$ Lawsonia inermis extract, $\mathrm{ME}=$ Mallotus phillipensis extract, NLCs= Nanolipid carriers

Fig. 1 indicates that the cream formulation has the desired viscosity required for semisolid formulation for proper packaging. It was found that the viscosity decreases as the rotational speed of viscometer increased suggesting shear thinning/pseudoplastic behavior at an ambient temperature where there is a decrease in viscosity by increasing shear rate favours easy spreadability further confirmed by spreadability test and tube extrudability (table 1). This shear-thinning behavior is a desirable property for topical preparations, as they should be thin during application and thick otherwise. 
Table 1: Spreading coefficient and tube extrudability of the AE, LE and ME NLC incorporated cream

\begin{tabular}{lll}
\hline S. No. & AE, LE and ME NLC loaded cream & \\
\cline { 2 - 3 } & Spreadability (gm. cm/s) & Extrudability (\%) \\
\hline 1 & 46.18 & $7.2 \%$ \\
2 & 46.06 & $7.4 \%$ \\
3 & 46.87 & $7.7 \%$ \\
(mean SD $\mathrm{n}=3)$ & $46.37 \pm 0.43$ & $7.43 \pm 0.25$ \\
\hline
\end{tabular}

Spreadability plays a considerable role in patient compliance and ensures uniform application of cream to a larger area of the skin. The low value of the spreadability coefficient of the cream was sufficient suggesting easy spreading and no signs of grittiness. Extrudability is a measure of removal of cream from the orifice of the container. The lower value of spreadability and tube extrudability indicates the lesser work required to spread the cream over the skin, which means formulation was easily spreadable by applying small amount of shear.

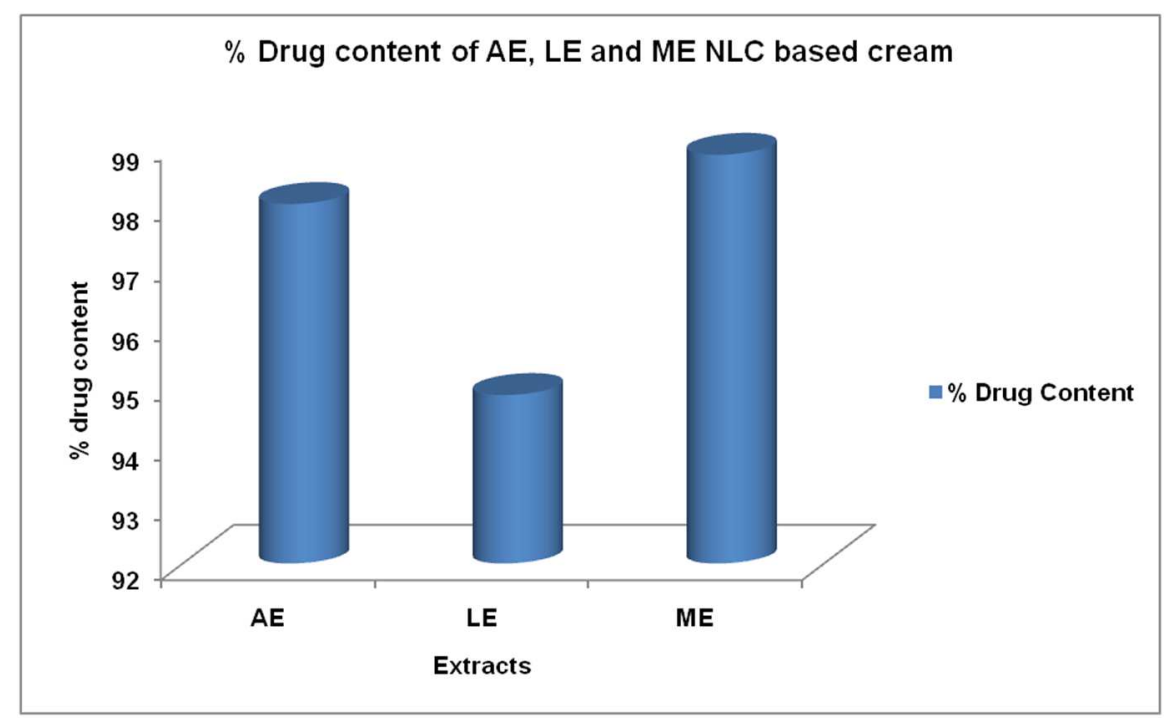

Fig. 2: Percentage drug content of AE, LE and ME NLC incorporated cream, Note: $(n=3)$ all data representing an average of 3 trials, given as mean $\pm \mathrm{SD}, \mathrm{AE}=$ Azadirachta indica extract, $\mathrm{LE}=$ Lawsonia inermis extract, $\mathrm{ME}=$ Mallotus phillipensis extract, $\mathrm{NLCs}=\mathrm{nanolipid}$ carriers

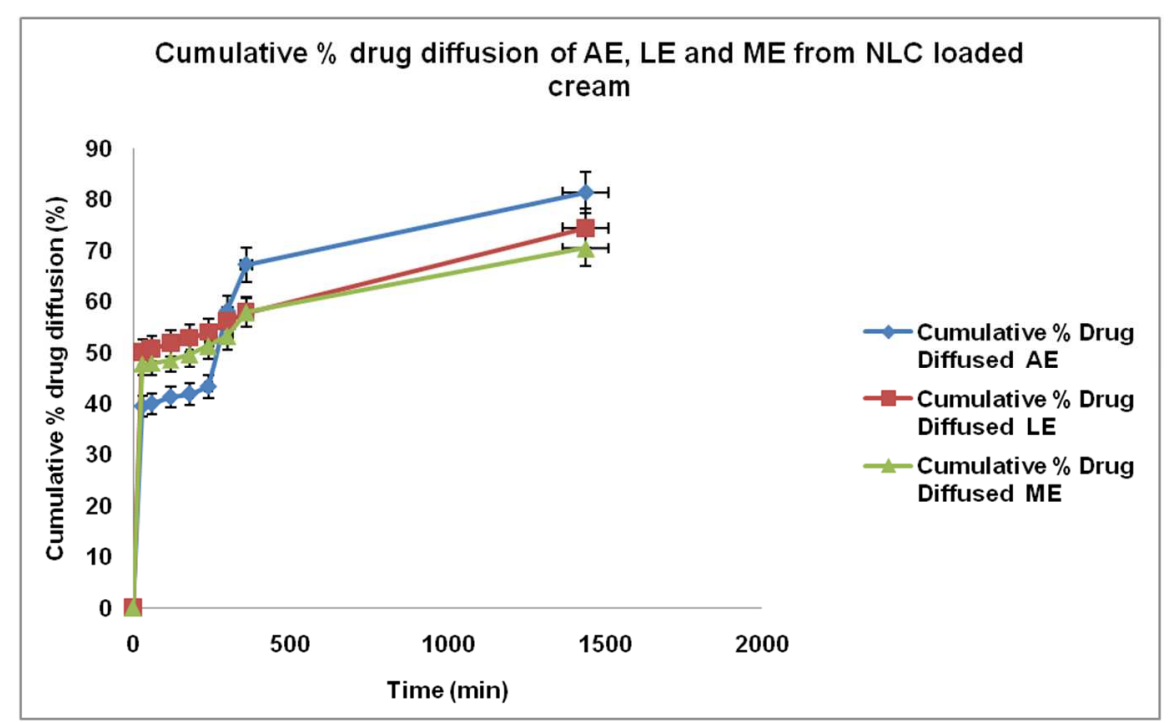

Fig. 3: Cumulative \% drug diffusion of AE, LE and ME from NLC based Cream, Note: (n=3) all data representing an average of 3 trials, given as mean $\pm \mathrm{SD}, \mathrm{AE}=$ Azadirachta indica extract, $\mathrm{LE}=$ Lawsonia inermis extract, $\mathrm{ME}=$ Mallotus phillipensis extract, $\mathrm{NLCs}=\mathrm{Nanolipid}$ Carriers

The results for \% drug content are depicted in fig. 2 that showed uniform distribution of drugs throughout the cream.

The data obtained from in vitro drug release studies also support and suggest complete and prolonged drug release from the NLCs through the cream base. During the preparation of NLCs, cooling from high temperature to room temperature favors the enrichment of the drug in the outer layers of the particles resulting in superficial entrapment causing initial burst release followed by prolonged drug release from the core of NLCs up to $24 \mathrm{~h}$ that was found to be 
$81.24 \pm 0.51 \%, 74.31 \pm 0.25 \%$ and $70.43 \pm 0.78 \%$ for $\mathrm{AE}, \mathrm{LE}$ and $\mathrm{ME}$ respectively as shown in fig. 3 .

\section{Lipid peroxidation assay}

Psoriasis has been associated with oxidative stress, which in turn is a function of lipid peroxidation as malondialdehyde (MDA) in the blood of psoriatic patients. The lipid peroxidation was determined based on the amount of thiobarbituric acid-reactive substances (TBARS) and with minor modifications in the HepG2 cells [32].
Oxidative stress was induced by treating the cells with freshly prepared H2O2. The results were expressed as percentage inhibition of lipid peroxidation as malondialdehyde (MDA) per milligram of protein. Lipid peroxidation Inhibition of the topical cream formulation of the NLCs with $\mathrm{IC}_{50}$ being $1497.3 \mu \mathrm{g} / \mathrm{ml}$. The results suggest inhibition of lipid peroxidation in the prepared NLC incorporated cream containing a combination of the extracts of $\mathrm{AE}$ LE and ME. Fig. 4 depicts the Anti-lipid peroxidation activity of AE, LE and ME from NLC based Cream.

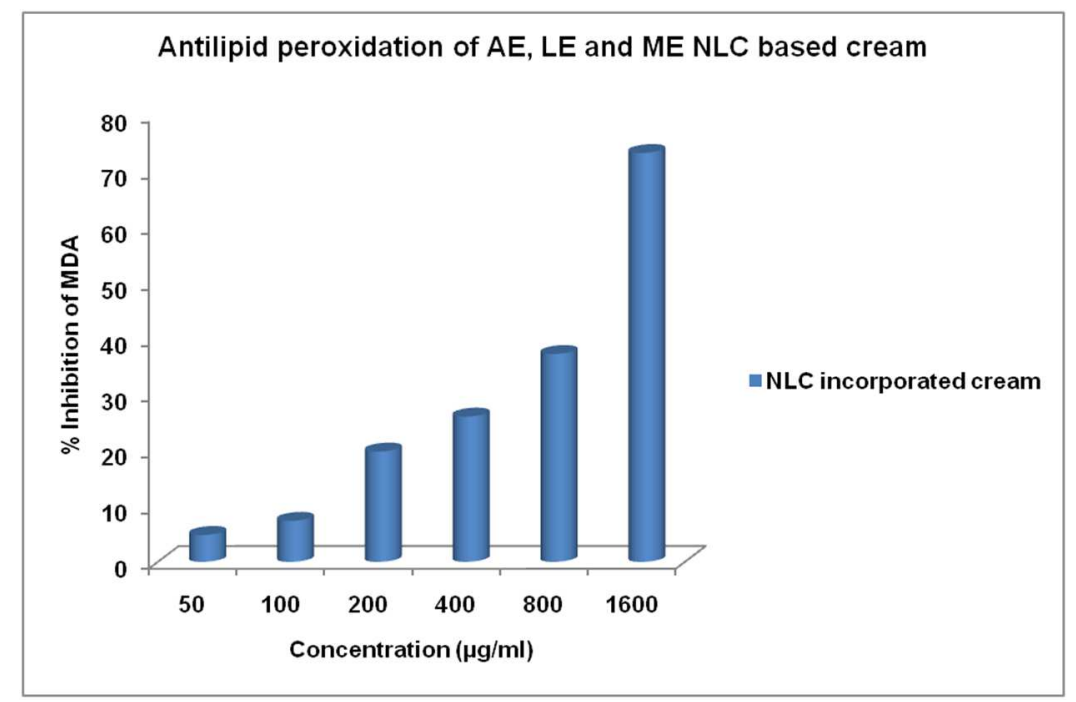

Fig. 4: Lipid peroxidation Inhibition of AE, LE and ME loaded NLCs based cream, Note: AE $=$ Azadirachta indica extract, $\mathrm{LE}=$ Lawsonia inermis extract, ME= Mallotus phillipensis extract, NLCs= Nanolipid Carriers, MDA= Malondialdehyde

\section{Nitric oxide scavenging assay}

Nitric oxide is a gaseous free radical that can react with superoxide anion and give rise to powerful free radicals called peroxynitrite radicals (NOO). It appears that the overproduction of uncontrolled formation peroxynitrite is an important factor in tissue-damaging mechanisms in chronic inflammation in psoriatic patients. This assay was performed to assess the anti-inflammatory effect of the selected drugs and formulations during the treatment of psoriasis.
Sodium nitroprusside in aqueous solution at physiological $\mathrm{pH}$ spontaneously generates nitric oxide, which interacts with oxygen to produce nitrite ions that can be measured using Griess reagent at $546 \mathrm{~nm}$ [33]. The percentage inhibition of Nitric Oxide was calculated. The results were expressed as Nitric Oxide Inhibition of AE, LE and ME NLC loaded cream that was observed to increase with the increase in dose as depicted in fig. 5. The AE, LE and ME NLC based cream possessed the Nitric Oxide Scavenging capability with an IC50 value of $697.9 \mu \mathrm{g} / \mathrm{ml}$.

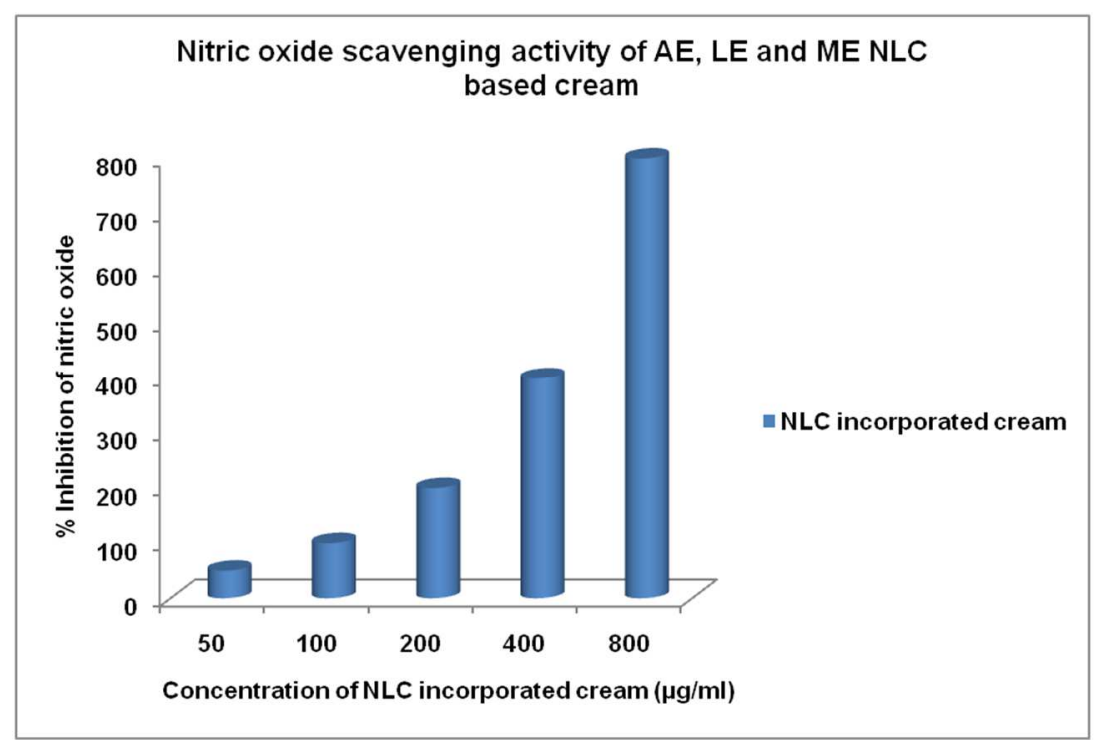

Fig. 5: Nitric oxide scavenging activity of AE, LE and ME NLC based cream, Note: AE= Azadirachta indica extract, LE= Lawsonia inermis extract, ME= Mallotus phillipensis extract, NLCs $=$ Nanolipid Carriers 


\section{Cytotoxicity studies for HaCat cell lines}

Psoriasis results from the hyper proliferation and abnormal differentiation of keratinocytes. The AE, LE and ME loaded NLC based cream were evaluated for anti-proliferative activities by MTT assay and found to have significant anti-proliferative effects, with IC 50 being $181.7 \mu \mathrm{g} / \mathrm{ml}$.

\section{DNA fragmentation studies on HaCat cell lines}

In the present investigation, we explored the propensity of keratinocytes derived from psoriatic plaques to undergo apoptosis. DNA fragmentation into oligonucleosomal ladders is characteristic of apoptosis. DNA fragmentations for AE, LE and ME loaded NLC based cream formulation was analyzed by gel electrophoresis. HaCat cells treated with samples of the topical cream formulation of the NLCs in the prescribed doses of $160 \mu \mathrm{g} / \mathrm{ml}, 320 \mu \mathrm{g} / \mathrm{ml}$ have shown dose-dependent increased DNA Fragmentation as compared with control. Overall, these results suggest that the DNA fragmentations were induced, a marker of apoptotic activity in the Cream.

\section{Mousetail model for psoriasis}

Advanced anti-psoriatic studies on animal models for topical cream loaded with AE, LE ad ME NLCs were conducted to evaluate and compare the safety and efficacy of nanoparticulate anti-psoriatic cream versus Clobetasol propionate $0.05 \%$ cream as topical applications in (psoriasis) using mouse tail method.

Compared with the normal control group, the epidermal thickness of mice tail skin treated with the standard drug (clobetasol propionate $0.05 \%$ cream) and test drug (AE, LE and ME loaded NLC based cream) groups were markedly reduced. Based on the results of the present study, it can be concluded that formulations of standard drug and test drugs may have potential anti-psoriatic activity.

\section{Rat ultraviolet ray-B photodermatitis model for psoriasis}

Rat Ultraviolet Ray-B photodermatitis model was applied to evaluate the antipsoriatic potential of nanoparticulate anti-psoriatic cream versus Clobetasol propionate $0.05 \%$ cream. Compared with the normal control group, the epidermal thickness of rat skin treated with standard drug (clobetasol propionate $0.05 \%$ cream) and test drug (AE, LE and ME loaded NLC based cream) groups were marked reduction in the thickness of the epidermal layer and inflammatory changes. Based on the results of the present study, it can be concluded that formulations of standard drug and test drugs may have potential anti-psoriatic activity.

\section{CONCLUSION}

The polyherbal nanoparticulate cream was successfully developed that met the relevant pharmaceutical characteristics. The cream possessed definite anti-proliferative activity against the HaCat cell lines. The experiments conducted under advanced pre-clinical trials confirmed the ability of the cream to suppress inflammation. Therefore, AE, LE and ME loaded NLC based cream could be considered as a potent and inexpensive anti-psoriatc agent. From the data obtained, it can be concluded that the developed AE, LE and ME loaded NLC based cream can be used for prolonged topical delivery of drugs for the management of Psoriasis and is a potential candidate for conducting further clinical studies.

\section{ACKNOWLEDGMENT}

The authors are grateful to the funding agency, Ministry of AYUSH, Government of India, New Delhi, India, for their financial support to carry out this work.

\section{AUTHORS CONTRIBUTIONS}

All the authors have contributed equally.

\section{CONFLICT OF INTERESTS}

Declared none

\section{REFERENCES}

1. Raghupatruni Jhansi Laxmi, R Karthikeyan, P Srinivasa Babu, RVV Narendra Babu. Formulation and evaluation of antipsoriatic gel using natural excipients. J Acute Disease 2013;2:115-21.
2. Tejinder Kaur Marwaha. Formulation development of antipsoriatic topical babchi oil emulgel. Res Rev: J Herbal Sci 2013;2:1-10.

3. Gazi Shaikh, Sadath Ali, SY Talmale, Ulhas S Surwase, Kadam Bhalchandra, Shaikh Luqman. Alternative medicine for psoriasis-a natural herbal ayurvedic treatment-a review. Int J Ayurvedic Herbal Med 2012;2:455-63.

4. Kaur T. Formulation development of anti-psoriatic topical babchi oil emulgel formulation development of anti-psoriatic topical babchi oil emulgel. Res Rev: J Herbal Sci 2017;2:1-14.

5. Chandrasekar R, Sivagami B. Alternative treatment for psoriasisa review. Int J Res Dev Pharm Life Sci 2016;5:2188-97.

6. Ghazanavi, Khaklid. Amraz-e-jildaur Ilaj-e-Nabvi. Farid Book Pvt Ltd; 2004. p. 123-136, 214-7, 257, 276.

7. Shashank Kumar, Pandey AK. Chemistry and biological activities of flavonoids: an overview. Sci World J 2013:1-16. Doi:10.1155/2013/162750

8. R Chaibi, M Romdhane, A Ferchichi, J Bouajila. Assessment of antioxidant, anti-inflammatory, anti-cholinesterase and cytotoxic activities of Henna (Lawsonia inermis) flowers. J Natural Products 2015;8:85-92.

9. Mayank Gangwar, RK Goel, Gopal Nath. Mallotus philippinensis muell. Arg (Euphorbiaceae): ethnopharmacology and phytochemistry review. BioMed Res Int 2014:1-13. https://doi.org/10.1155/2014/213973

10. Li B, Ge ZQ. Nanostructured lipid carriers improve skin permeation and chemical stability of idebenone. AAPS PharmSciTech 2012;13:276-83.

11. Leelapornpisid P, Chansakaow S, Na-boon long S, Jantrawut $P$. Development of cream containing nanostructured lipid carriers loaded marigold flowers extract for anti-wrinkle application. Int J Pharm Pharm Sci 2014;6:5-9.

12. Musallam Almousallam, Claudia Moia, Huijun Zhu. Development of nanostructured lipid carrier for dacarbazine delivery. Int Nano Lett 2015;5:241-8.

13. Shadab Khan, Ghazala Mulla, Kiran Bhise. Antipsoriatic potential of polyherbal paste. Res Rev: J Herbal Sci 2013; 8:20-32.

14. Bhise K, Khan S, Mulla G. Topical anti-psoriatic nanoparticulate drug delivery system. Int J Appl Pharm 2020;12:76-85.

15. KP Rao, Khaliq K, Kharat SS, Sagare P, Sk P. Preparation and evaluation of o/w cream for skin psoriasis. Int J Pharma Bio Sci 2010;1:1.

16. Mahapatra Annada Prasad, Mishra Dipak Kumar, Panda Prabhudutta. Formulation and evaluation of cream prepared from corton spardiflorus morong and their wounf healing activity. Int J Res Ayurveda Pharm 2012;3:803-7.

17. Shankar R, Sarangi B, Gupta R, Pathak K. Formulation and characterization of polyherbal cream for skin manifestations. J Asian Assocation Schools Pharm 2016;5:360-6.

18. Razi M, Khan U, Hussain M, Masood S, Ur S, Nazir R. Formulation design and in vitro characterization of etoricoxib cream for the treatment of rheumatoid arthritis. Iranian J Pharm Sci 2014;10:93-104.

19. Divya Pingili, Deepa Amminbavi, Archana Awasthi, Faisal Mohd Shamim Khan. Formulation, evaluation and in votro antibacterial screening of herbal gel containing Manilkara hexandra (roxb) dubard leaf extract. Int J Pharm Sci Res 2018;9:702-7.

20. Kotta Ktanthi Kumar, K Sasikanth, M Sabareesh, N Dorabu. Formulation and evaluation of diacerien cream. Asian J Pharm Clin Res 2011;4:93-8.

21. Helal DA, El-rhman DABD, Abdel-halim SA, El-nabarawi MA. Formulation and evaluation of fluconazole topical gel. Int J Pharm Pharm Sci 2012;4:12-4.

22. Ohkawa H, Ohishi N, Yagi K. Assay for lipid peroxides in animal tissues by thiobarbituric acid reaction. Anal Biochem 1979;95:351-8.

23. Panasenko OM, Evgina SA, Driomina ES. Hypochlorite induces lipid peroxidation in blood lipoproteins and phospholipid liposomes. Free Radical Biol Med 1995;19:133-40.

24. Yokozawa T, Wang ST, Chen PC, Hattori M. Inhibition of nitric oxide release by an aqueous extract of tinospora tuberculata. Phytother Res 2000;14:51-3. 
25. T Mosmann. Rapid colorimetric assay for cellular growth and survival: application to proliferation and cytotoxicity assays. J Immunol Methods 1983;65:55-63.

26. Colombo I, Sangiovanni E, Maggio R, Mattozzi C, Zava S, Corbett $\mathrm{Y}$. HaCaT cells as a reliable in vitro differentiation model to dissect the inflammatory/repair response of human keratinocytes. Medistors of Inflammation 2017:1-12. https://doi.org/10.1155/2017/7435621.

27. Li Z, Yu J, Liu L, Wei Z, Ehrlich ES. Coxsackievirus A16 infection induces neural cell and non-neural cell apoptosis in vitro. PLOS One 2014;9:1-10.

28. Takada M, Noguchi A, Sayama Y, Kurohane Kaneko Y, Ishikawa T. Inositol 1,4,5-trisphosphate receptor-mediated initial $\mathrm{Ca}\left(2^{+}\right)$ mobilization constitutes a triggering signal for hydrogen peroxide-induced apoptosis in INS-1 $\beta$-cells. Biol Pharm Bull 2011;34:954-8.
29. Singhal M, Kansara N. Cassia tora linn cream inhibits psoriasis in mouse tail model. Pharm Crops 2012;3:1-6.

30. Manmohan Singhaland Niraj Kansara. Cassia tora linn cream inhibits ultraviolet-B-induced psoriasis in rats. ISRN Dermatol; 2012. p. 16.

31. Nakaguma H, Kambara T, Yamamoto T. Rat ultraviolet ray B photodermatitis: an experimental model of psoriasis vulgaris. Int J Exp Pathol 1995;76:65-73.

32. Nagamani M, Prahaladu P, Vijayababu PVSS, Ashalata K, Kusuma Kumari P, Kumari KL. Lipid peroxidation product as a marker of oxidative stress in psoriasis-a case-control study in north coastal Andhra Pradesh. IOSR J Dent Med Sci 2015;14:2279-861.

33. Ignacio NRS, Ferreira PLJ, Almeida BM, Kubelka FC. Nitric oxide production by murine peritoneal macrophages in vitro and in vivo treated with Phyllanthus tenellus extracts. J Ethnopharmacol 2001;74:181-7. 